\title{
Observations of pressure effects on the creep of ice single crystals
}

\author{
David M. Cole \\ U.S. Army Cold Regions Research and Engineering Laboralory, Hanover, New Hampshire 03755, U.S.A.
}

\begin{abstract}
Experiments performed on ice single crystals oriented for basal slip indicate that the steady-state creep rate is only marginally affected by confining pressure up to $19 \mathrm{MPa}$, at a constant absolute temperature of $263 \mathrm{~K}$. The observations contradict earlier work at similar pressures and the disparity is examined in terms of experimental errors.
\end{abstract}

\section{INTRODUCTION}

A series of confined compressive-creep experiments were conducted on single crystals of pure ice in an effort to establish the activation volume for basal glide. The ultimate intent of the work is to use pressure effects on the easy-glide creep rate to shed light on the physical processes involved in the mobility of basal plane dislocations.

Since the work of Rigsby (1958), it has generally been accepted that there is virtually no pressure effect on the easy-glide creep rate provided that the experiments are performed at a constant homologous temperature $T_{\mathrm{H}}=T / T_{\mathrm{II}}$ (where $T$ is the temperature of the experiments and $T_{\mathrm{M}}$ is the pressure-sensitive melting point). rather than a constant absolute temperature. The experiments described here produced a different result: pressure had very little effect on the easv-glide creep rate at constant absolute temperature. The following sections present a brief review of creep and pressure effects before focusing on the experimental results and possible explanations for the disagreement with earlier work.

\section{SINGLE-CRYSTAL CREEP}

Butkovich and Landauer (1958), Higashi 1967, 1969). Weertman 1973, 1983 and Homer and Glen 1978 present original data, useful tabulations and analyses of single-crystal creep behavior. In summary, the easy-glide creep behavior follows a power law with observed values of the stress exponent $n$ ranging from 1.3 to 4.0 , depending on the experimental conditions. A value of $n \approx 2$ is generally accepted. The activation energy $Q$ for creep is typically in the range of 0.6 to $\approx 0.7 \mathrm{cV}$. Experiments employing constant deformation rates rather than constant loads produce essentially the same values of $n$ and $Q$. The latter experiments show a welldefined peak strength followed by a sharp drop off and give no evidence of work hardening.

Jones and Brunet (1978) found an activation energy of $0.73 \mathrm{eV}$ for single crystals that decreased slightly with increasing temperature. Upon careful analysis, consider- ing temperature effects on the modulus, Homer and Glen (1978) determined that the activation energy for easy glide increases monotonically and rather slightly as temperature increases, and noted that both the activation energy and the stress exponent are stress-dependent $n=2.0$ for stresses below 2.0 MPa, and $n=2.5$ for higher stresses; $Q=0.67 \mathrm{eV}$ for stresses above 2.0 $\mathrm{MPa}$ and $Q=0.61 \mathrm{eV}$ for lower stresses).

\section{PRESSURE EFFECTS ON CREEP}

\section{Single crystals}

Rigsby (1958) performed the first confined-creep experiments on ice single crystals to address concerns amongst glaciologists regarding the behavior of ice at the bottom of thick ice sheets. He performed experiments at shear stresses of approximately 0.256 and $0.368 \mathrm{MPa}$ at temperatures ranging from -1 to $-20^{\circ} \mathrm{C}$, at either atmospheric pressure or approximately $30 \mathrm{MPa}$. After finding that the deformation rate at constant $T$ increased with confining pressure, he conducted an experiment in which the temperature was lowered appropriately to maintain the specimen at a constant number of degrees below the pressure-sensitive melting point $T_{\mathrm{N}}$. The results led to the conclusion that with such compensation for the pressure effect on the melting temperature, the basal creep rate was essentially independent of pressure for the stated conditions. Interestingly, this result was contrary to the expectations of many at that time. Rigsby cautioned that the reported strain rates were averages for intervals before and after the pressure and temperature changes) and that the ice was not in steady-state creep.

\section{Polycrystalline ice}

Although the rate-controlling processes in polycrystalline ice are expected to be different from those in single-crystal ice, a brief review provides some useful insight and illustrates the extent to which pressure corrections have been applied to creep data. 
Haefeli and others (1968) observed decelerating creep throughout tests performed at very low creep-stress levels, and found that a pressure of $29.5 \mathrm{MPa}$ brought about an approximately $30 \%$ decrease in strain rate when the temperature was lowered to account for the pressuremelting effect. Jones and Chew (1983) performed creep experiments on polycrystalline ice up to $60 \mathrm{MPa}, T=$ $-9.6 \mathrm{C}$, and $\sigma_{\text {creep }}=0.47 \mathrm{MPa}$. Temperature was not adjusted downward to compensate for the pressure effect on $T_{\mathrm{M}}$. Jones and Chew observed that the creep rate decreased slightly for pressures up to approximately $15 \mathrm{MPa}$, and increased for pressures greater than $30 \mathrm{MPa}$. Averaging values of strain rate for a number of specimens, they arrived at activation volumes of $3.2 \times 10^{-5} \mathrm{~m}^{3} \mathrm{~mol}^{-1}$ and $-5.5 \times 10^{-5} \mathrm{~m}^{3} \mathrm{~mol}^{-1}$, for the lowand high-pressure regions, respectively.

One specimen tested at several pressure levels (in fig. 2 of Jones and Chew (1983)) exhibited a significantly lower activation volume on its first pressure cycle, estimated by the present author to be approximately $2 \times 10^{-6} \mathrm{~m}^{3} \mathrm{~mol}$, which is close to the value of $4.1 \times 10^{6} \mathrm{~m}^{3} \mathrm{~mol}^{-1}$ for the dielectric relaxation process in ice (Taubenberger and others, 1973). This particular measurement eliminates the specimen variability effects which could easily overshadow or distort a slight pressure effect.

Mizuno (1992) presented the results of confined-creep experiments performed at temperatures of $-0.8^{\circ}$ to $-2.3^{\circ} \mathrm{C}$ and pressures up to $35 \mathrm{MPa}$. That work indicated a slight increase in the high-temperature creep rate with pressure, when pressure-melting effects were not considered. However, when the results were interpreted in terms of the homologous temperature, a decrease in strain rate by a factor of 1.52 was associated with the pressure change, along with a slight increase in activation energy above $T_{\mathrm{H}}=0.985$. At lower temperatures, there was a minimal pressure effect on the creep rate, in accord with Jones and Chew (1983).

\section{EXPERIMENTAL DETAILS}

The present experiments employed a patented test fixture with the unique feature of a pressure-activated loading piston mounted within the confining chamber (Fig. 1). A complete description of the cell, along with details of the hydraulic and electrical systems, specimen preparation, calibration, data reduction and analysis are given elsewhere (Cole, 1992, in press). For the specimen length and range of the displacement gauge employed, the precision of the strain measurement was $2 \times 10^{-5}$. The pressure vessel was placed in an insulated tank containing a mixture of ethylene glycol and water, with temperature control provided by a refrigerated circulating bath. The system was located in a cold room maintaining an average temperature of $-8.5^{\circ} \mathrm{C}$. As a result of the mass of the tank and cell, the interior temperature of the cell was very stable.

The test specimens were taken from material grown in bulk from seed crystals. The process used degassed and distilled water frozen at a rate of approximately $30 \mathrm{~mm} \mathrm{~d}^{-1}$. Rough-cut specimens were taken with basal planes oriented at $45^{\circ}$ to the eventual axis of loading and subsequently finished to diameter using a warm-die extrusion method.

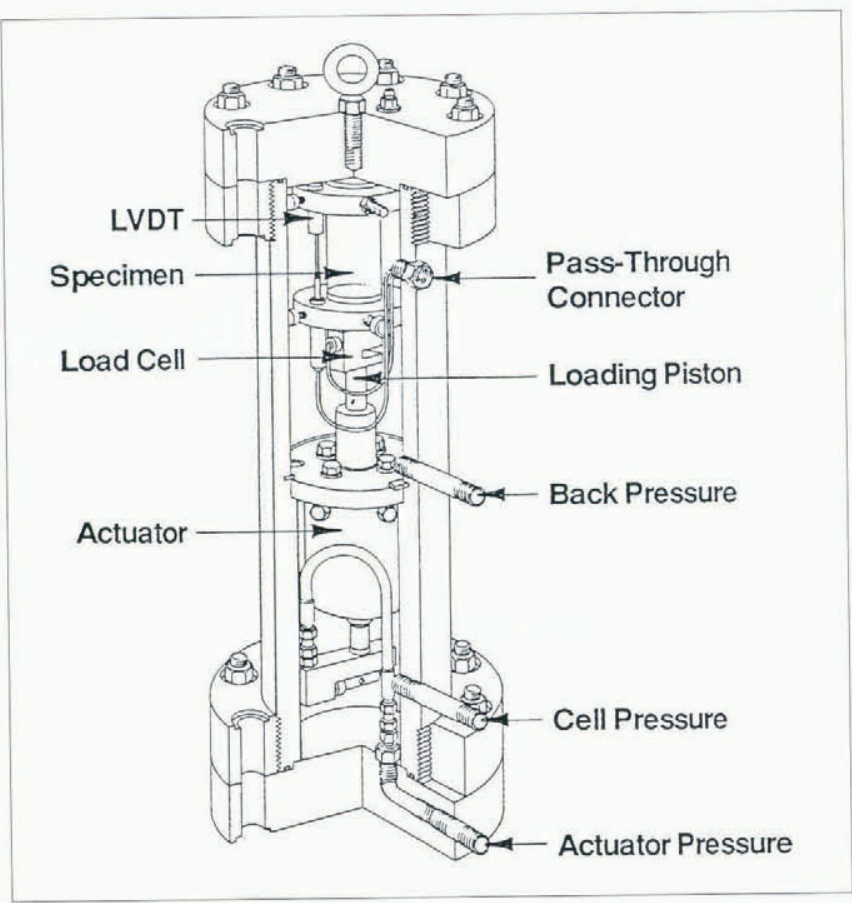

Fig. 1. The confined-creep cell.

\section{RESULTS}

Table 1 summarizes the experimental results. For the data points over which the strain-rate measurements were made, the nominal stress levels were maintained with a standard deviation of $\pm 5 \mathrm{kPa}$ or less for specimens $\mathrm{SC}-1$ and -2 , and generally within $\pm 1 \mathrm{kPa}$ for specimen SC-4. The strain interval indicates the creep strains over which the specimen experienced the nominal stress. In general, the reported strain rate was determined over the part of the strain interval for which the stress control was most consistent. The exception was test 27JAN2 on specimen $\mathrm{SC}-2$, for which the average stress was $0.201 \pm 0.03 \mathrm{kPa}$. The lack of good stress control is reflected in the high standard deviation of the strain rate.

In the following plots, the stress level appearing under the specimen number indicates the confining pressure for all the data in a given figure. The stress levels appearing next to the plotted data indicate the axial compressive creep stresses. Figure 2 demonstrates a typical steady-state response at atmospheric pressure before and after a change in the creep stress. Each part of the curve is linear in a macroscopic sense, although noise in the deformation measurement systems caused point-to-point scatter. The symbols indicate actual data points, and the solid line in the expanded region is the result of the smoothing routine.

Figure 3 illustrates the behavior of a specimen subjected to a sequence of application and removal of a $0.2 \mathrm{MPa}$ creep stress. Upon reapplication of the stress, the strain rate resumes its previous trajectory within approximately 0.001 strain. The initial decreasing strain rate in the individual segments has been omitted from this plot.

The steady-state response for specimen SC-1 at several pressure levels is plotted in Figure 4. This specimen appears to exhibit steady-state behavior only at the very end of the atmospheric-pressure test performed just prior to the $14.1 \mathrm{MPa}$ pressurization. However, it is clear from Figure $4 \mathrm{~b}$ that the specimen essentially began the 


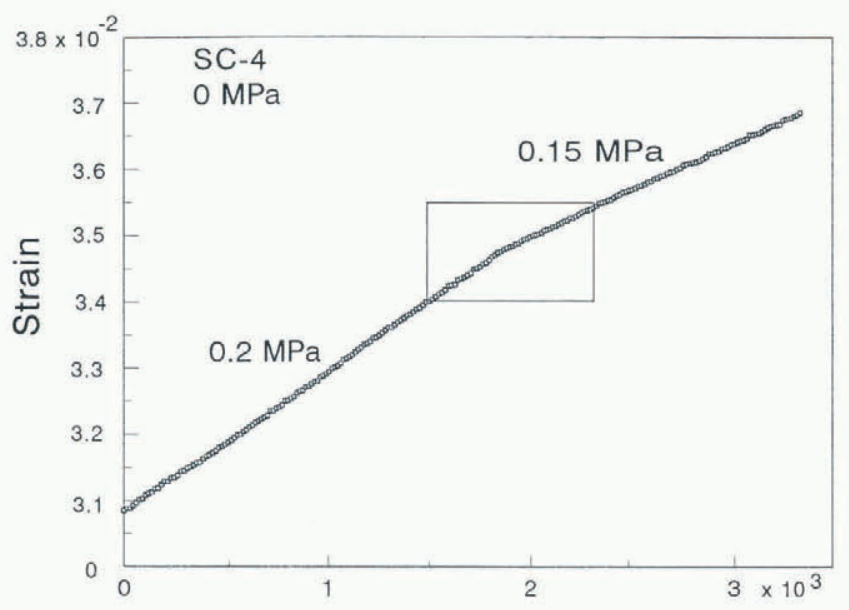

$\mathbf{a}$

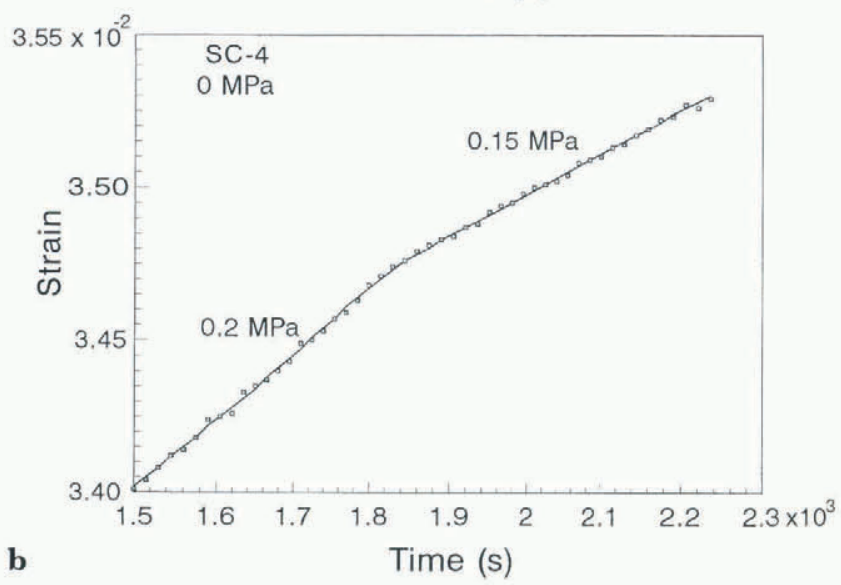

Fïg. 2. Typical response to a decrease in the creep stress during sleady slate (lest No. 10FEB2). (a) Strain is time. (b) Expanded view of the boved region in (a). The solid line is the result of the smoothing routine, and the symbols represent aclual data points.

variable, causing very slight decreases in strain rate in most cases, yet with slight increases found for SC-1. The $0.15 \mathrm{MPa}$ crecp-stress level shows a gradual increase over the full pressure range. The same specimen under the 0.20 MPa creep-stress level shows a decrease over the pressure

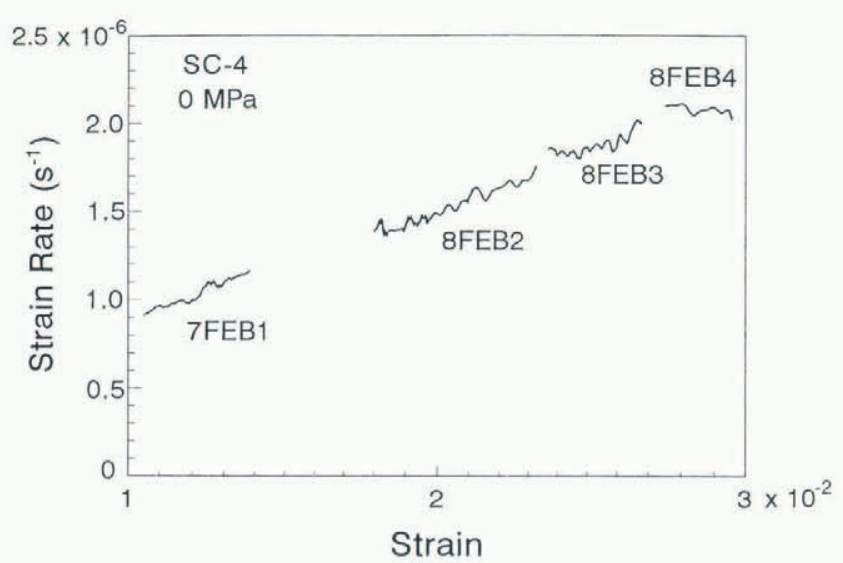

Fig. 3. Strain rale os strain for several loading interruptions; test numbers as indicated. Gaps in the data correspond to either periods of load adjustment or straining under the 0.15 MPa stress level.

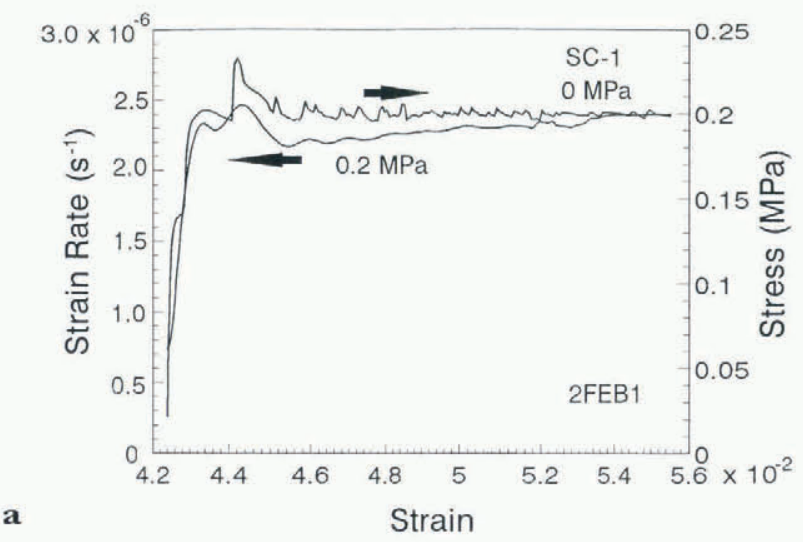

b
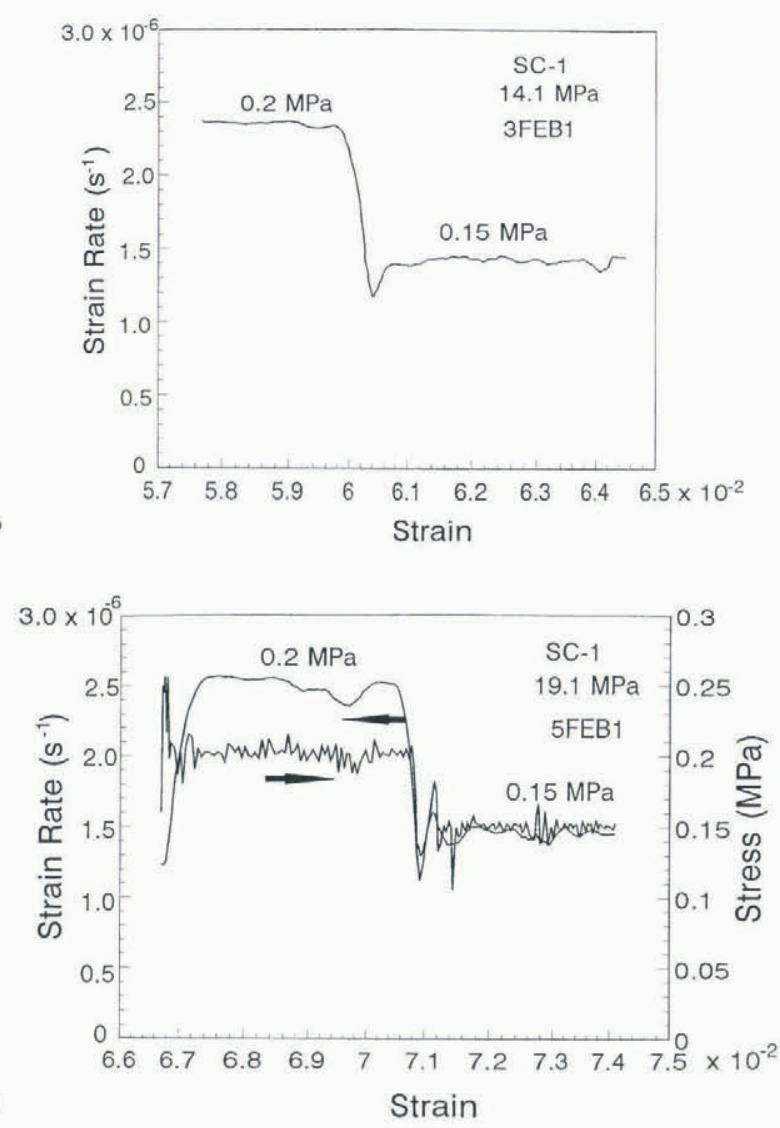

d

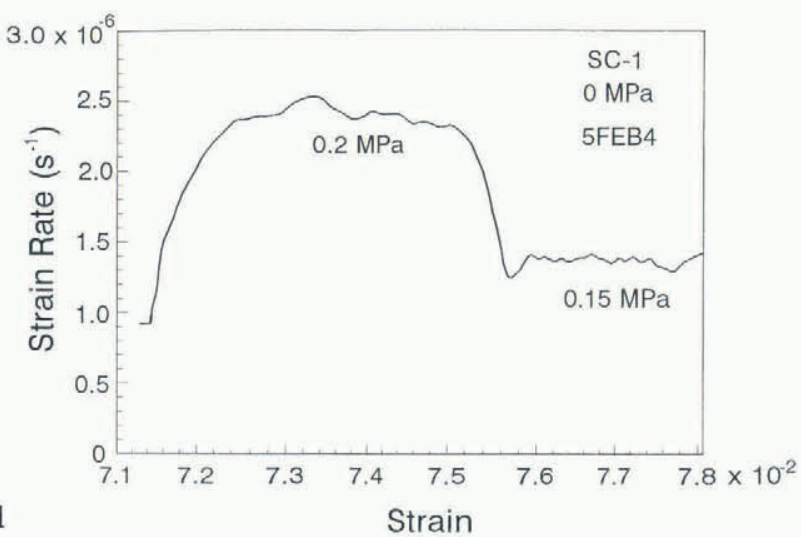

Fïg. 4. Experimental results for specimen SC-1. (a) Specimen achieving steady-slate creep al almospheric pressure. The unfiltered creep stress is also plotled. (b) Steady-state response at 14.1.MPa confining pressure and creep stresses of 0.20 and $0.15 \mathrm{MPa}$. (c) Continuation of straining at a confining pressure of $19.1 \mathrm{MPa}$. (d) Final straining al almospheric pressure. 
Table 1. Summary of confined-creep experiments

\begin{tabular}{|c|c|c|c|c|c|c|c|c|}
\hline \multirow{2}{*}{$\begin{array}{l}\text { Specimen } \\
\mathrm{SC}-1\end{array}$} & \multirow{2}{*}{$\begin{array}{l}\text { Test.No. } \\
\text { 29JAN3 }\end{array}$} & \multirow{2}{*}{$\begin{array}{c}T \\
{ }^{\circ} \mathrm{C} \\
-9.57\end{array}$} & \multirow{2}{*}{$\begin{array}{c}\sigma_{3} \\
\mathrm{MPa} \\
0\end{array}$} & \multirow{2}{*}{$\begin{array}{l}\sigma_{\text {creep }} \\
\mathrm{MPa} \\
0.20\end{array}$} & \multicolumn{2}{|c|}{$\begin{array}{l}\text { Strain interval } \\
\qquad\left(\times 10^{2}\right)\end{array}$} & \multirow{2}{*}{$\begin{array}{c}\dot{\varepsilon} \\
\frac{\left(\times 10^{6} \mathrm{~s}^{-1}\right)}{-}\end{array}$} & \multirow{2}{*}{$\begin{array}{c}\varepsilon_{\mathrm{mn}} \\
\left(\times 10^{4}\right) \\
0.10\end{array}$} \\
\hline & & & & & 0 & 0.497 & & \\
\hline & $30 \mathrm{JAN} 1$ & -9.64 & 0 & 0.20 & 0.484 & 1.530 & & 1.47 \\
\hline & $30 \mathrm{JAN} 5$ & -9.56 & 13.8 & 0.20 & 1.510 & 2.170 & & 1.43 \\
\hline & $31 \mathrm{JANl}$ & -9.51 & 14.1 & 0.20 & 2.027 & 2.551 & & \\
\hline & [FEB] & -9.67 & 14.1 & 0.20 & 3.387 & 4.696 & & 1.64 \\
\hline & 2FEB1 & -9.72 & 0 & 0.20 & 4.609 & 6.105 & $2.39 \pm 0.003$ & 3.81 \\
\hline & 3 FEB1 & -9.66 & 14.0 & 0.20 & 5.724 & 6.005 & $2.36 \pm 0.01$ & - \\
\hline & & & & 0.15 & 6.063 & 6.451 & $1.43 \pm 0.01$ & 1.34 \\
\hline & 5 FEB1 & -9.61 & 19.1 & 0.20 & 6.671 & 7.081 & $2.55 \pm 0.01$ & - \\
\hline & & & & 0.15 & 7.141 & 7.411 & $1.46 \pm 0.03$ & 3.51 \\
\hline & 5 FEB4 & -9.62 & 0 & 0.20 & 7.143 & 7.537 & $2.37 \pm 0.03$ & \\
\hline & & -9.52 & 0 & 0.15 & 7.558 & 7.806 & $1.38 \pm 0.01$ & 1.64 \\
\hline SC-2 & 4JANI & -5.0 & 0 & 0.30 & 0 & 0.501 & - & 0.18 \\
\hline & $15 \mathrm{JANI}$ & -9.77 & 0 & 0.33 & 0.483 & 1.633 & & 0.26 \\
\hline & 2FEBI & -9.72 & 0 & 0.20 & 4.609 & 6.105 & $2.39 \pm 0.003$ & \\
\hline & 15JAN2 & -9.77 & 0 & 0.33 & 1.607 & 1.941 & - & 0.21 \\
\hline & $17 \mathrm{JAN} 2$ & -9.67 & 6.9 & 0.20 & 4.110 & 4.670 & & - \\
\hline & $26 \mathrm{JAN}$ & -9.77 & 3.5 & 0.30 & 6.104 & 6.440 & - & - \\
\hline & $26 \mathrm{JAN} 2$ & -9.65 & 3.5 & 0.20 & 6.760 & 7.030 & $1.52 \pm 0.03$ & 1.30 \\
\hline & 27JAN1 & -9.85 & 0 & 0.20 & 6.910 & 7.628 & $1.88 \pm 0.02$ & - \\
\hline & 27JAN2 & -9.73 & 6.9 & 0.20 & 8.294 & 9.185 & $1.39 \pm 0.02$ & 0.80 \\
\hline $\mathrm{SC}-4$ & $6 \mathrm{FEBl}$ & -9.66 & 0 & 0.30 & 0 & 0.397 & - & - \\
\hline & & & & 0.20 & 0.437 & 0.788 & - & 1.71 \\
\hline & 7FEBI & -9.69 & 0 & 0.20 & 0.942 & 1.429 & - & - \\
\hline & & & & 0.15 & 1.450 & 1.726 & - & 1.50 \\
\hline & 8FEB2 & -9.58 & 0 & 0.20 & 1.799 & 2.327 & - & 0.50 \\
\hline & 8FEB3 & -9.61 & 0 & 0.20 & 2.289 & 2.696 & & 0.60 \\
\hline & 8FEB4 & -9.63 & 0 & 0.20 & 2.651 & 2.962 & $2.08 \pm 0.02$ & \\
\hline & & & & 0.15 & 3.004 & 3.272 & $1.33 \pm 0.03$ & 0.59 \\
\hline & 10FEB2 & -9.67 & 0 & 0.20 & 3.016 & 3.454 & $2.08 \pm 0.01$ & - \\
\hline & & & & 0.15 & 3.531 & 3.729 & $1.42 \pm 0.02$ & 1.51 \\
\hline & 10FEB3 & -9.62 & 0 & 0.15 & 3.595 & 3.810 & $1.48 \pm 0.02$ & 0.59 \\
\hline & $11 \mathrm{FEB} 2$ & -9.66 & 18.3 & 0.20 & 3.799 & 4.338 & - & 2.10 \\
\hline & 11 FEB6 & -9.60 & 18.3 & 0.20 & 4.437 & 5.412 & $2.77 \pm 0.03$ & \\
\hline & 11FEB7 & -9.60 & 18.3 & 0.15 & 5.485 & 6.029 & $1.74 \pm 0.02$ & 4.12 \\
\hline & 12FEBI & -9.63 & 0 & 0.20 & 5.216 & 5.678 & $2.80 \pm 0.01$ & - \\
\hline & & & 0 & 0.15 & 5.733 & 6.116 & $1.77 \pm 0.03$ & 3.40 \\
\hline
\end{tabular}

14.1 MPa experiment in steady state. This, and the fact that this specimen acquired very nearly the same strain rate in the final test at atmospheric pressure, indicates that it was in steady state for the entire period. Figure $4 \mathrm{a}$ also presents unfiltered values of the creep stress. The ability to control the creep stress improved with experience, and the variability in the latter part of the data in Figure 4a may be considered an average performance. Subsequent plots include the creep stress when it helps to explain variations in the strain-rate data.

Specimen SC-1 experienced no stresses that were significantly higher than the intended level during this pressurization sequence. As a consequence, its dislocation density remained relatively constant, as evidenced by the fact that after pressurization the strain rate returned essentially to its initial steady-state value. The steadystate strain rates observed in these experiments all fall well within the expected limits of single-crystal behavior, as summarized by Duval and others (1983), for the prevailing stress and temperature.

Specimen SC-4 experienced a brief accidental overload during one of its high-pressure runs and this is believed to be why the strain rate does not return to its initial value during the final atmospheric-pressure test. As the overload occurred early in the high-pressure test, a relatively constant dislocation structure is believed to apply for the steady-state strain rates at $18.3 \mathrm{MPa}$ and those of the final atmospheric-pressure test. Figure 5 shows plots of strain rate and creep stress in some cases, vs strain for specimen SC-4.

The results of experiments on specimens SC-1 and -4 cover the widest pressure range and thus offer the best opportunity to expose a pressure effect. The stability of the temperature and stress levels for tests on those two specimens was considerably better than on SC-2, which was the first to be tested.

The steady-state strain rates are plotted as a function of pressure in Figure 6. The effects of pressure are 


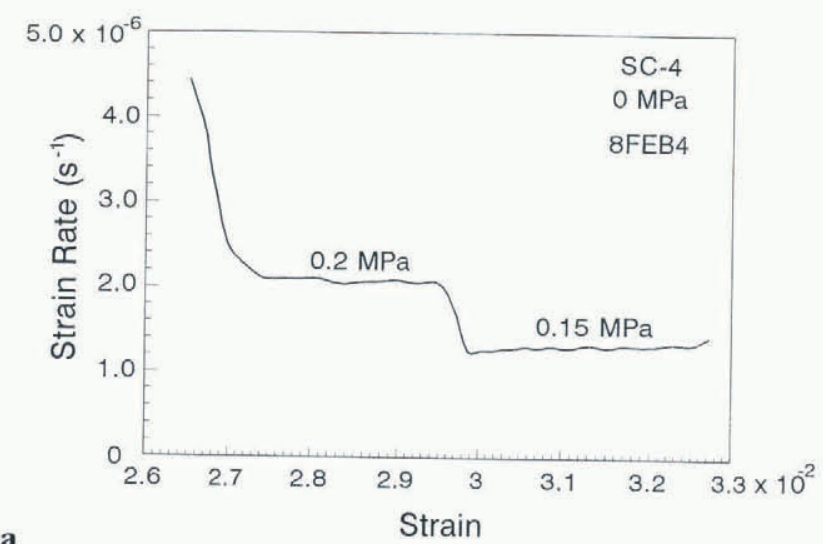

a
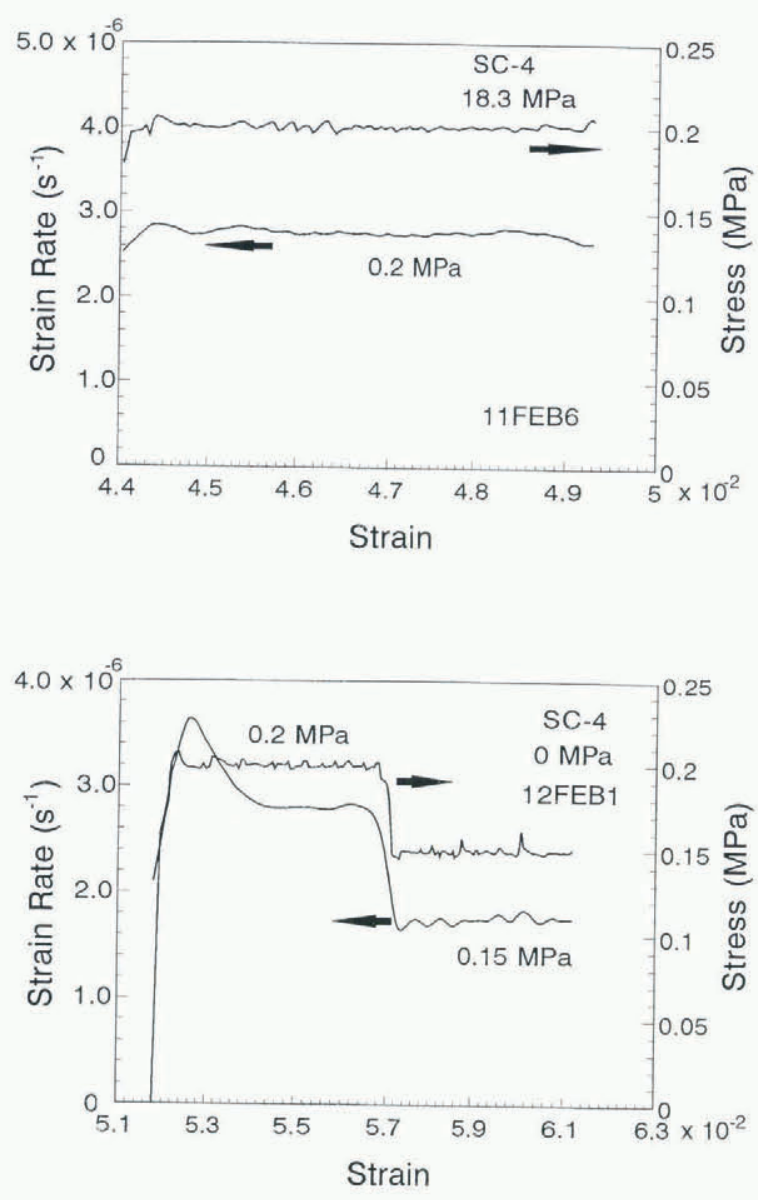

Fïg. 5. Experimental resulls for specimen SC-4. (a) Straining at almospheric pressure. Vote that the strain rate for the 0.15.MPa creep stress is increasing slightly. (b) Sleady-state creep at 18.3. MPa confining pressure and 0.20 MPa creep stress. (c) Final straining al atmospheric pressure.

increment to $14 \mathrm{MPa}$, followed by an increase for the next pressure increment to $19.1 \mathrm{MPa}$. With the exception of $\mathrm{SC}-2$, the decreases in strain rate amount to $1-2 \%$, and are thus of the same magnitude as the coefficient of variation associated with the strain-rate calculations. The temperature variations during steady-state creep have a low standard deviation $(\approx \pm 0.04 \mathrm{C})$, and calculations indicate (Cole, in press) that this has no significant impact on the results.

The anelastic strain values, taken as the total strain

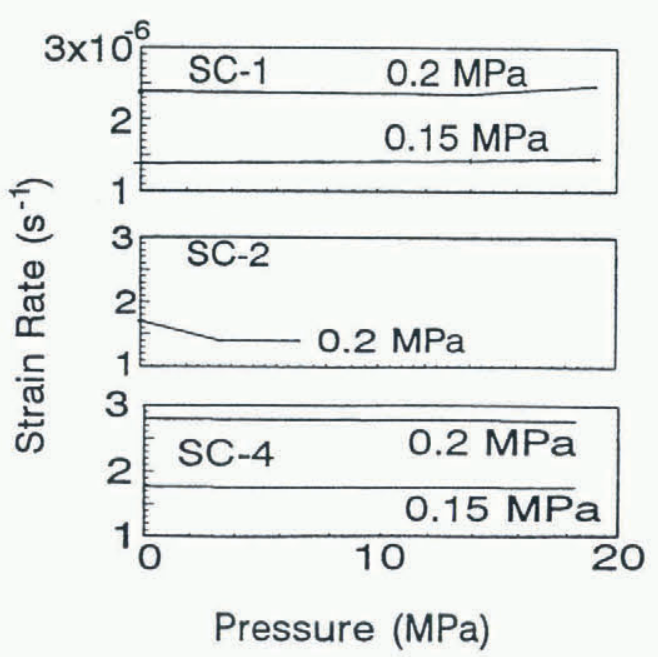

Fig. 6. Steady-stale creep rale as a function of pressure.

recovered in time after removal of the creep stress less the elastic strain, ranged from $0.8 \times 10^{4}$ to $4.1 \times 10^{4}$.

The specimens developed well-defined slip bands (Fig. 7a) as expected for the $45^{\circ}$ orientation of the basal planes to the stress axis. Thin sections (Fig. 7b) revealed evidence of slip lines in the crystals commensurate with the macroscopic deformations. When allowed to etch in the cold-room atmosphere for a period of time, the microtomed and polished surfaces of the sections developed rows of etch pits along the slip lines with spacing of approximately $1 \mathrm{~mm}$.

\section{DISCUSSION}

The salient features of the confined-creep experiments may be summarized as follows:

1. After a very brief transient period, the strain rate increased to a steady-state value.

2. Steady-state creep was quickly reestablished after removal and reapplication of the creep stress.

3. At constant absolute temperature, slight pressure effects that were variable with respect to sign were observed over the pressure range 0 19.1 MPa. No gross changes in steady-state creep rate occurred.

The first two of these observations are important in establishing the validity of the experimental procedures. The essential aspects of single-crystal behavior evident in the present experiments are in agreement with the observations in the literature on compressive creep. On the other hand, the shear experiments performed by Rigsby 1958 exhibited either a continuous increase or decrease in strain rate. It is possible that the double shear device employed in that work in some way influenced the observations, as discussed below. Rigsby's method of unloading the specimen during periods of pressure change and temperature equilibration proved effective in the present study.

The fact that no gross change in strain rate occurred over the pressures studied stands in contrast to Rigsby's observations on single crystals. The strain rates at constant temperature in those experiments increased by 

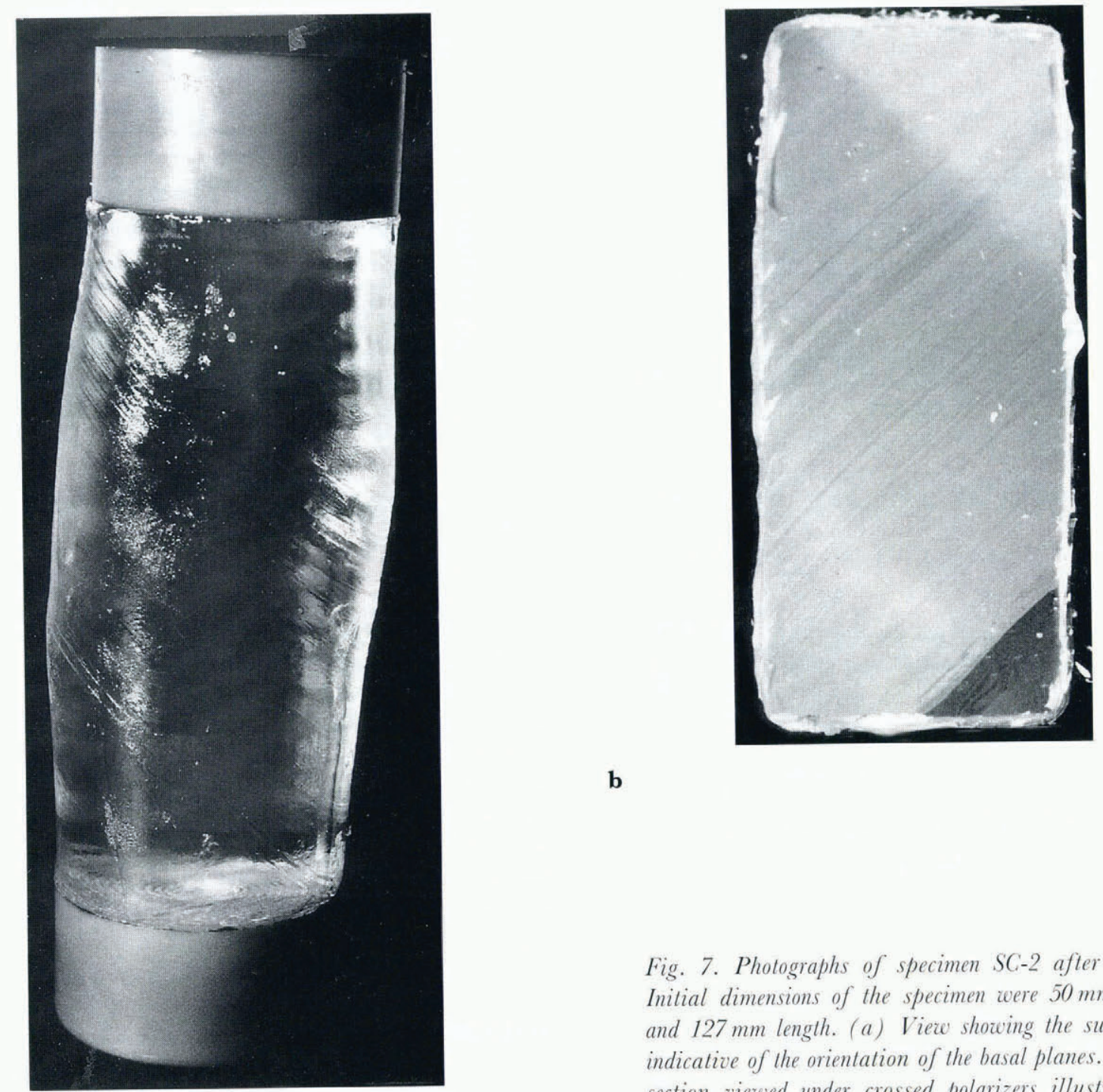

b

a

a factor of $1.5-2$ for a pressure change of $\approx 30 \mathrm{MPa}$, at temperatures both higher and lower than in the present work. An effect of this magnitude would have been easily detected at the pressures employed in the present experiments. Two possible explanations for this critical difference in behavior are now examined.

Rigsby's deformation readings included contributions of the coarsely serrated interface between both parts of the shear specimen and its brass mount. Stress concentrations associated with this geometry, and with the order-ofmagnitude difference between the bulk modulus of ice and that of the brass fixture, would result in an enhanced creep rate for the interfacial region. The contribution of this region to the measured deformation might also increase significantly at higher pressures and for temperatures close to the melting point. Additionally, the inability of the specimens to achieve steady-state creep in those experiments must call into question the validity of the experimental technique.

As noted, Rigsby attributed the observed increase in strain rate with pressure to the fact that the melting point decreases with pressure. (The relationship between pressure and the change in the melting point is $\partial T=0.074^{\circ} \mathrm{CMPa}^{\prime}$ (Hobbs, 1974). By keeping the homologous temperature constant, he found that the

strain rate was virtually unaffected by a confinement change from 1 to $27.4 \mathrm{MPa}$. It was thus concluded that the only effect of pressure on creep rate was through its effect on the homologous temperature. With one exception (Jones and Chew, 1983), this approach has been taken in the analysis of other confined-creep experiments on ice. Interestingly, it has been employed despite the fact that the more recent work on polycrystalline ice at lower temperatures (as discussed above) indicates that there is a minimal effect on creep rate for pressures below $35 \mathrm{MPa}$. In such cases, performing experiments at constant homologous temperature results in creep rates that decrease with pressure. The maximum pressure of 19.1 $\mathrm{MPa}$ in the present study, for example, depresses the melting point by $1.41^{\circ} \mathrm{C}$, increasing the homologous temperature from 0.9645 to 0.9695 . Arguing that the homologous temperature should be held constant implies that the elevated pressure actually decreased the strain rate by $\approx 17 \%$ (calculated by considering $\Delta T=1.41^{\circ} \mathrm{C}$ with $Q=0.7 \mathrm{eV}$ ).

There are two factors which weaken the case for applying the melting-point correction indiscriminately. First, the present findings and the results for polycrystalline ice at pressures below $35 \mathrm{MPa}$ show no significant pressure effects at temperatures near $-10^{\circ} \mathrm{C}$ and below. 
Secondly, the effects observed in this pressure range, but at higher temperatures, are variable, with their magnitude increasing with proximity to the melting point. Thus, pressures up to $35 \mathrm{MPa}$ are capable of accelerating creep only at temperatures very close to the melting point. The first of these factors obviates the need for applying the pressure-melting interpretation in cases where the creep rate does not increase significantly with pressure. As usually applied to creep-test results, the pressure-melting argument indicates that the effect of pressure is independent of temperature, and thus offers no explanation for the variable pressure effects.

It remains to be shown experimentally what effect higher pressures will have on the easy-glide creep rate. It was not possible to examine behavior at substantially higher pressures with the system employed in the present experiments. The system's design pressure of $20 \mathrm{MPa}$ was based on indications in the literature that, unfortunately, were very misleading as a consequence of experimental artifacts.

The potential importance of proton rearrangement in the dislocation-glide process has been recognized since the work of Weertman (1963), and the observed pressure effects are now examined in that regard. The maximum pressure applied in the creep experiments would produce at best a $4 \%$ reduction in the creep rate if proton rearrangement alone controlled dislocation motion. Of the two most reliable creep experiments, one indicates increases of $8.6 \%$ and $5.8 \%$ for the steady-state creep rate while the other indicates decreases of $1 \%$ and $1.7 \%$ for creep-stress levels of 0.20 and $0.15 \mathrm{MPa}$, respectively, and approximately the same pressure change. Given the relatively minor pressure effects observed, the inherent scatter in creep-rate measurements, and the relatively weak pressure effect expected from a drag mechanism based on proton rearrangement, the importance of that mechanism can be neither confirmed nor eliminated on the basis of the experimental findings. It is clear, however, that carefully performed experiments at much higher pressures are required to use pressure effects as a link between basal dislocation creep and proton rearrangement.

\section{SUMMARY AND CONCLUSIONS}

The creep experiments on single crvstals oriented for easy glide were performed at $-9.6 \mathrm{C}$, and under pressures of up to $19.1 \mathrm{MPa}$. The crystals exhibited steady-state creep after straining several per cent, at which point a series of tests was performed at elevated pressure.

For the prevailing experimental conditions, the pressure effect at constant absolute temperature on the easy-glide creep rate was small, with mixed indications as to its sign. Although firm conclusions cannot be drawn regarding the activation volume associated with easy glide, the results do not support the indications in early work to the effect that strain rate increases significantly with pressure at all temperatures unless adjusted for the effect of pressure on the melting point.
The evidence of a small pressure effect, coupled with the inherent variability in creep behavior, indicates the need for experiments at much higher pressures to establish the activation volume for easy-glide creep in ice.

\section{ACKNOWLEDGEMENTS}

The author expresses his appreciation for the help and guidance of Professor J. Weertman, Northwestern University, Evanston, Illinois, during the course of this work. The author gratefully acknowledges the support of the Corps of Engineers Long Term Training Program, CRREL's In-house Laboratory Independent Research Program and Northwestern University. The superior technical services of J. Morse, D. Lambert, T. Arnold, C. Williams and E. Berliner were critical to the success of the experiments.

\section{REFERENCES}

Butkovich, T.R. and J.K. Landauer. 1958. The flow law for ice. International Association of Scientific I1ydrology) Publication 47 Symposium at Chamonix 1958 - Physics of the Morement of the Ice), 318327.

Cole, D. M. 1992. Hydrostatic pressure effects on the internal friction and creep of ice. Ph.D. thesis. Northwestern University, Evanston.

Cole, D. M. In press. The effect of pressure on the creep and internal friction of ice. CRREI. Rep,

Duval, P., M.F. Ashby and I. Anderman. 1983. Rate-controlling processes in the creep of polycrystalline ice. 7. Phos. Chem., 8721 , 40664074 .

Hacfeli, R.. C. Jaccard and M. de Quervain. 1968. Deformation of polycrystalline ice under combined uniaxial and hydrostatic pressure. International Association of Scientific Mrdrology Publication 79 General Assembly of Bern 1967 Showe and Jee. 341-344.

Higashi, A. 1967. Mechanisms of plastic deformation in ice single crystals. In Oura. H.. ed. Plessios of snow and ice. International Conference on Low Temperature Science... 1966... Proceedings. Vol. I. Parl I. Sapporo, Hokkaido University. Institute of Low Temperature Science, 277289.

Higashi, A. 1969. Mechanical properties of ice single crystals. In Richl N.. B. Bullemer and H. Engelhardt, eds. Pliysics of ice. Proceedings of the International Simposium on the Phssics of Ice. ... 1968. New York. Plenum Press, $197-212$.

Hobles, P. V. 1974. Le phrsics. Oxford. Clarendon Press.

Homer, D. R. and J. W. Glen. 1978. The creep activation energies of ice. j. Glaciol.. 2185$), 429444$.

Jones. S.J. and J. G. Brunet. 1978. Deformation of ice single crystals close to the melting point. J. Gilaciol., $2185,445-455$.

Jones, S. and H. А. М. Chew. 1983. Creep of ice as a function of hydrostatic pressure. J. I'hys. C.hem., 821 , 40644066.

Mizuno, Y. 1992. High temperature creep of polycrystalline ice under hydrostatic pressure. In Macno, N. and T. Hondoh, eds. Physics and chemistry of ice. Sapporo. Hokkaido University Press, 434439.

Rigsby, G. P. 1958. Elfect of hydrostatic pressure on velocity of shear deformation of single ice crystals. J. Glaciol., $324,273-278$.

Taubenberger, R., M. Hubmann and H. Gränicher. 1973. Effect of hydrostatic pressure on the dielectric properties of ice Ih single crystals. In Whalley. E.. S.J. Jones and L. W. Gold, eds. Plysies and chemistry of ice. Ottawa, Royal Society of Canada, 194198.

Weertman, J. 1963. The Eshelby Schoeck viscous dislocation damping mechanism applied to the steady-state creep of ice. In Kingery, W. D.. ed. Lee and snow; properties, processes, and applications. Cambridge, M. M.I.T. Press, $28-33$.

Weertman. J. 1973. Creep of ice. In Whalley, E.. S.J. Jones and L. W. Gold. eds. Physics and chemisty of ice. Ottawa, Royal Society of Canada, $320-337$.

Weertman. J. 1983. Creep deformation of ice. Ammu. Rev. Earlh Planet. Sci., 11. 215240. 